Revista de Economia Política, vol. 28, $n^{\circ} 3$ (111), pp. 443-453, julho-setembro/2008

\title{
"School Accountability" no Brasil: experiências e dificuldades
}

\section{EDUARDO DE CARVALHO ANDRADE*}

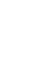

School accountability in Brazil: experiences and difficulties. This paper analyses the most important experiences with school accountability policy (SA) in Brazil. The analysis suggests that their impacts on the quality of education are not significant due to the fact that: (i) either it does not incorporate a system in which the school is responsible for the students' performance; (ii) or the incentive schemes are not appropriately designed. Finally, it discusses the main barriers to the adoption of an efficient SA at the national level in Brazil.

Keywords: school accountability, education, education policy, incentive schemes, student performance, test scores, proficiency tests

JEL Classification: I21; I28.
\end{abstract}

\section{INTRODUÇÃO}

A partir da década de 1990, vários estados nos Estados Unidos decidiram adotar a política de school accountability (SA). Essa política compreende, em linhas gerais, as seguintes características: (i) estabelecimento de padrões educacionais mínimos para cada ano escolar; (ii) realização de testes de proficiência para averiguar os conhecimentos adquiridos pelos alunos; (iii) divulgação dos resultados dos testes por escola; e (iv) adoção como objetivo explícito de política a melhoria no desempenho dos estudantes nestes testes.

Adicionalmente, alguns estados incorporaram um outro aspecto na sua política de SA. Eles estipularam que os professores/diretores da escola são responsáveis pelo desempenho dos alunos nos testes de proficiência. Desta forma, foi criado um sistema de incentivos nos quais professores/diretores recebem bonificações ou são

\footnotetext{
*Ibmec São Paulo. Rua Quatá, 300. São Paulo, e-mail: eduardo.andrade@isp.edu.br. Submetido: Agosto 2006; Aceito: Março 2007.
} 
penalizados em função das notas dos alunos. Seguindo a nomenclatura utilizada em Hanushek e Raymond (2004), os estados que adotam esta característica na sua política de SA são chamados consequential states. Os outros, que simplesmente divulgam os resultados dos testes de proficiência dos alunos, sem atrelar um sistema de bonificações/penalidades, são chamados de report card states. ${ }^{1}$

A partir da análise da experiência de SA nos Estados Unidos, é possível enfatizar alguns pontos. ${ }^{2}$ Primeiro, ao longo da década de 1990, ou seja, antes portanto da aprovação do No Child Left Behind Act, somente os estados que incorporaram na SA um política agressiva, cujos professores/diretores são penalizados ou bonificados em função do desempenho dos seus alunos, registraram um aumento nas notas dos alunos nos testes de proficiência. Em outras palavras, a política de SA somente foi eficaz nos chamados consequential states. Nos report card states, não houve nenhuma melhora. ${ }^{3}$ Segundo, esse crescimento foi significativo, sendo algo em torno de até 0,3 desvio-padrão.

Terceiro, não existe evidência de que essa melhoria seja resultado de comportamentos oportunísticos por parte dos professores. Como discutido na literatura, existem pelo menos duas maneiras que esses podem "inflar" artificialmente as notas dos alunos e serem recompensados por isto: incentivar os piores alunos a abandonar a escola ou elevar as taxas de reprovação. Desta forma, os piores alunos não realizam as provas de proficiência, aumentando as notas da escola, sem que isto represente uma melhoria na qualidade da educação. ${ }^{4}$ Quarto, são incluídos no arcabouço institucional que rege a política de SA alguns mecanismos para evitar gaming. Por exemplo, na legislação da Carolina do Norte, um dos itens que compõem o indicador que avalia a escola é a porcentagem dos alunos que obtêm o padrão de competência do estado nos exames de proficiência. Isto limita a possibilidade de conseguir vantagens ao se adotar a estratégia de incentivar os piores alunos a sair da escola.

Por fim, existe o reconhecimento de que vários fatores, fora do controle das escolas, como o background familiar, afetam o desempenho dos estudantes. Portanto, para o sistema de incentivos ser eficaz, é fundamental que professores/diretores sejam recompensados com base na sua real contribuição para os resultados

\footnotetext{
${ }^{1}$ Com a aprovação, em 2001, pelo Congresso dos Estados Unidos do No Child Left Behind Act, todos os estados americanos são obrigados a incluir na sua política de SA um sistema de penalidades/bonificações. Ao mesmo tempo, eles são obrigados a definir um plano que garanta que os alunos, num prazo de doze anos, adquiram um nível considerado satisfatório de proficiência nas disciplinas básica. Para maiores detalhes, ver Hanushek (2004).

${ }^{2}$ Para uma revisão da experiência de SA nos Estados Unidos, ver Andrade (2006).

${ }^{3}$ Para maiores detalhes sobre esses resultados, ver Hanushek e Raymond (2004) e Carnoy e Loeb (2002).

${ }^{4}$ Esses comportamentos oportunistas são conhecidos na literatura por gaming. Para a teoria sobre o assunto, ver Brickley, Smith e Zimmerman (2004). Hanushek e Raymond (2004) e Jacob (2002) são exemplos de estudos que não constatam a presença de gaming nos estados que adotaram a SA nos Estados Unidos.
} 
obtidos pelos alunos. Ou seja, no valor adicionado da escola. ${ }^{5} \mathrm{O}$ estado do Texas, por exemplo, adotou a seguinte política. As escolas são divididas em grupos com características semelhantes e elas competem pelos prêmios e bonificações dentro do seu grupo. Desta forma, procura-se eliminar as principais diferenças dos fatores não escolares que afetam o desempenho dos estudantes.

Tendo como base esta experiência nos Estados Unidos, é possível analisar as experiências com SA no Brasil. Esse é exatamente um dos objetivos deste trabalho. Inicialmente, examinar as características das principais experiências com SA no Brasil, nos âmbitos federal, estadual e municipal. À luz da experiência americana, pode-se avaliar quais são as principais falhas destas políticas no Brasil e os seus possíveis (ou ausência de) impactos sobre a qualidade da educação. O segundo objetivo é discutir as principais dificuldades para se implantar no Brasil uma política de SA que seja, de fato, eficaz em melhorar a qualidade da educação.

Além desta introdução, esse trabalho tem três seções. A seguinte analisa algumas experiências da política de SA no Brasil. A terceira seção discute os principais empecilhos para a adoção da SA no país. A última seção apresenta as conclusões.

\section{SCHOOL ACCOUNTABILITY NO BRASIL}

Essa seção discute as experiências com a política de SA no Brasil. Primeiro, é enfatizado que não existe uma política de SA implantada em âmbito nacional, semelhante à vigente atualmente nos Estados Unidos. Somente alguns aspectos de uma versão completa de SA estão presentes. Em seguida, são analisadas as principais experiências com SA nos âmbitos estadual e municipal, enfatizando as principais falhas de concepção.

\section{SA no âmbito federal}

Existem diferenças importantes entre o atual estágio da política federal de SA no Brasil em comparação com a atual em vigência nos Estados Unidos.

Como mencionado na introdução, nos Estados Unidos, a partir da aprovação do Congresso em 2001, a política educacional nacional é aquela que consta do No Child Left Behind Act (NCLB). Segundo este, todo estado americano tem que estruturar uma política com os seguintes parâmetros: (i) estabelecimento de padrões educacionais mínimos para cada ano escolar; (ii) realização de testes de proficiência para averiguar os conhecimentos adquiridos pelos alunos; (iii) tornar público os resultados das escolas nestes testes; (iv) adotar como objetivo explícito de política a melhoria no desempenho dos estudantes nestes testes; (v) responsabilizar os professores/diretores da escola pelo resultado dos alunos.

Tendo estes parâmetros como base, pode-se dizer, em contraste, que não é

\footnotetext{
${ }^{5}$ Para mais detalhes, ver Hanushek e Raymond (2002).
} 
adotada uma política de SA, em âmbito nacional, no Brasil. A partir da segunda metade da década de 1990, o governo federal implantou os pontos (i) e (ii): um sistema de avaliação nacional dos ensinos fundamental e médio, estabelecendo o que seria desejável que os alunos soubessem em cada ano escolar. O governo federal institui o SAEB (Sistema Nacional de Avaliação da Educação Básica), que é um teste para avaliar o conhecimento em português e matemática de uma amostra de alunos nos ensinos fundamental ( $4^{\circ}$. e $8^{\circ}$. séries) e médio $\left(3^{\circ}\right.$. série). A primeira edição desta prova, depois de corrigidos alguns problemas técnicos nas suas primeiras aplicações, ocorreu em 1995. Para realizar essa prova, é escolhida uma amostra representativa do universo dos estudantes. Além disto, criou o Enem (Exame Nacional de Ensino Médio) em 1998, que tem como ênfase a avaliação do perfil de saída dos egressos do ensino médio. ${ }^{6}$ Ao contrário do Saeb, no entanto, o aluno que conclui o ensino médio decide se realiza ou não o Enem. ${ }^{7}$ Em 2005, o governo criou a Prova Brasil. As principais diferenças em relação ao Saeb são que ela não é uma avaliação amostral, pois abrange a totalidade dos estudantes matriculados em escolas públicas urbanas, e somente avalia alunos do ensino fundamental $\left(4^{\circ}\right.$. e $8^{\circ}$. séries).

Somente em 2006, o governo federal incorporou o ponto (iii) da política de SA, ou seja, passou a divulgar os resultados por escola, tanto da Prova Brasil quanto do Enem. Não foram adotados os pontos (iv) e (v) da política de SA: estipular a melhoria no desempenho dos alunos como objetivo da política educacional e responsabilização. Pode-se dizer, então, que o governo federal adotou uma política branda de SA.

Espera-se contar com a pressão da sociedade para que os professores/diretores das escolas, cujos alunos tenham tido desempenhos insatisfatórios, adotem políticas adequadas para reverter os resultados. Segundo a classificação adotada por Hanushek e Raymond (2004), discutida na introdução, a política adotada no Brasil corresponderia àquela "sem conseqüência", a vigente nos report card states.

Fica evidente, portanto, que existe espaço para o governo federal adotar uma política de SA mais agressiva. Tendo como base a experiência americana, não se deve esperar uma melhoria significativa na qualidade da educação simplesmente seguindo a atual política. Seria necessário que fosse adotado um mecanismo de incentivos no qual professores/diretores sejam considerados responsáveis pelo desempenho dos alunos e sejam remunerados de acordo com este.

\section{SA nos âmbitos estadual e municipal}

Nos âmbitos estadual e municipal, existem algumas poucas experiências de SA, basicamente de dois tipos.

\footnotetext{
${ }^{6}$ Para maiores informações sobre essas provas, ver o site http://www.inep.gov.br.

${ }^{7}$ Várias universidades utilizam o resultado do Enem como parte do processo de seleção dos seus alunos.
} 
No primeiro tipo, alguns governos, na sua esfera, basicamente repetem o mesmo padrão de política aplicado pelo governo federal. Três exemplos nesta linha são os seguintes: a prefeitura de São Paulo e os Estados de São Paulo e Minas Gerais.

A prefeitura de São Paulo criou o Sistema de Avaliação de Aproveitamento Escolar. Inicialmente, a partir de 2006, os alunos das escolas municipais das $4^{\circ}$. e $8^{\circ}$. séries prestarão exames de escrita e leitura. O programa prevê que, no futuro, os alunos de todas as séries do ensino fundamental (da $1^{a}$ à $8^{a}$ série) realizarão provas de diferentes disciplinas. ${ }^{8}$ Assim como no governo federal, existe uma disposição de divulgação das notas por escolas, apesar de não constar na lei, como agora é feito no caso do Saeb. Portanto, até o momento, não existe nenhuma diferença entre a política do município de São Paulo e a do governo federal. Ambas não possuem um sistema de bonificação/penalidade para professores/diretores atrelado ao desempenho dos alunos. Existe, na verdade, uma superposição de iniciativas, com os mesmos alunos sendo testados da mesma forma. No futuro, o sistema de avaliação da prefeitura propõe-se ser mais completo. No entanto, não parece ser razoável que outras prefeituras no Brasil sejam capazes de replicar o sistema de avaliação da cidade de São Paulo, por não terem condições financeiras para tal. De fato, é bastante questionável que tal tipo de política deva ser feita em âmbito municipal. A possibilidade de obter ganhos de escala realizando provas como esta em esfera estadual parece ser mais adequada.

O segundo exemplo é o do Estado de São Paulo. O governo paulista criou o Saresp (Sistema de Avaliação de Rendimento Escolar do Estado de São Paulo) em 1996. Até 2003, a prova era feita por amostragem e somente para algumas séries. Em 2004, passou a ser aplicada a todos os alunos de todas as séries. Somente em 2005 a prova de matemática foi incluída. Anteriormente, havia somente questões de leitura e escrita. A prova foi suspensa no ano de 2006 e ainda não se sabe quando e se será novamente aplicada.

Os alunos das escolas municipais localizadas no Estado de São Paulo podiam participar do Saresp, desde que os municípios resolvessem aderir espontaneamente e pagassem o custo por aluno, que era de R \$1,35 reais em 2005.

A importante diferença em relação ao governo federal é que as notas das provas não eram divulgadas, como é feito por escola no caso da Prova Brasil a partir de 2006. Desta forma, o sistema de avaliação do Estado de São Paulo, por ser pouco transparente, não contava com a potencial pressão da comunidade sobre as escolas com pior rendimento para melhorarem a qualidade do ensino. A política do Estado também não contemplava nenhum sistema de penalidade/bonificação para professores/diretores em função da performance dos estudantes. Neste sentido, ele era exatamente igual à política vigente na esfera federal até o ano de 2005. $\mathrm{Na}$ classificação de Hanushek e Raymond (2004), ele não pode ser considerado nem um exemplo de report card states nem de consequencial states.

No caso da política do Estado de São Paulo, o objetivo do sistema era sim-

\footnotetext{
${ }^{8}$ Os alunos da $1^{a}$ à $4^{a}$ série realizarão provas de português, matemática, ciências, história e geografia. Já os alunos da $5^{\mathrm{a}}$ à $8^{\mathrm{a}}$ série farão provas de português, matemática, história, geografia, química, física e biologia. Para mais detalhes, ver www.prefeitura.sp.gov.br.
} 
plesmente que os seus resultados servissem de parâmetros para que a Secretaria de Educação adotasse e sugerisse políticas mais eficazes para as escolas mais problemáticas. Desta forma, diferentemente da política de SA, a responsabilidade última pelo desempenho dos alunos era da Secretaria e somente indiretamente recaía sobre professores/diretores.

O terceiro e último exemplo é o do Estado de Minas Gerais. Primeiro, na década de 1990, criou um exame em que todos os alunos das escolas públicas estaduais realizavam e os resultados eram amplamente divulgados. Neste sentido, funcionava exatamente como um exemplo de report card states. Adicionalmente, no entanto, foi dado um certo protagonismo aos conselhos escolares. Esses foram incentivados a examinar os resultados das escolas e fazer pressão para que melhorassem. No entanto, por não responsabilizar diretores/professores pelos resultados, não pode ser considerado um caso de consequencial state. ${ }^{9}$

Em 2000, o mesmo Estado de Minas Gerais criou o Sistema Mineiro de Avaliação da Educação Pública (SIMAVE). Ele tem basicamente as mesmas características da atual política do governo federal. Os alunos da $4^{\circ}$. e $8^{\circ}$. séries realizam provas de português, matemática, história, geografia e ciências. Os resultados são divulgados por escola, mas sem atribuir "conseqüências" para professores/diretores. As suas diretrizes são claras exatamente no sentido contrário: "a avaliação não tem como objetivo premiar ou punir [...] (e) não tem o objetivo de avaliar individualmente os alunos e muito menos os professores". ${ }^{10}$

O segundo tipo de política de SA adotada no Brasil vai além do que simplesmente tornar público os resultados das provas por escola. Três exemplos nesta linha são os seguintes: Estados do Paraná, Ceará e Rio de Janeiro. ${ }^{11}$

O Estado do Paraná instituiu o "Boletim da Escola" em 2001. A Secretaria de Educação compilava informações sobre cada escola a partir de três fontes: desempenho das escolas nos testes de proficiência; informações do censo escolar, como taxas de reprovação e evasão escolares; e opiniões coletadas junto a diretor, alunos e pais. Interessante notar a possível preocupação com gaming, ao coletar informações específicas existentes no censo escolar. Não existia nenhuma preocupação em atrelar resultados à bonificação/penalidade para diretores/professores. Esperava-se que a pressão da comunidade, principalmente através da associação de pais, fosse suficiente para melhorar a qualidade da educação nas escolas. O programa não sobreviveu à mudança de governo e foi abandonado em 2003 pela nova administração.

O Estado do Ceará estabeleceu um prêmio educacional chamado "Escola do Novo Milênio-Educação Básica de Qualidade no Ceará” em 2001. Ficou estabele-

\footnotetext{
${ }^{9}$ Agradeço a um dos pareceristas por chamar a atenção para esta experiência no Estado de Minas Gerais.

${ }^{10}$ Citação extraída de http://www.simave.ufjf.br/simave/, aonde mais detalhes sobre o programa podem ser obtidos.

${ }^{11}$ Para mais detalhes de cada uma destas experiências, ver a apresentação de Nigel Brooke em http:// www.iets.inf.br/article.php3?id_article=337.
} 
cido um único critério para avaliar a escola: a média das notas dos seus alunos nos testes de proficiência. Bonificações, mas não penalidades, passaram a ser distribuídas em função deste indicador. As 100 escolas com maior média ganham prêmios, sendo $100 \%$ do valor para as 50 primeiras e $50 \%$ para as 50 seguintes. ${ }^{12}$

Esse sistema de incentivos incorre em duas falhas de concepção. Primeiro, não capta de forma adequada a verdadeira contribuição da escola para o aprendizado, pois não leva em consideração o valor agregado da mesma. Por exemplo, as escolas cujo alunato tenha um perfil socioeconômico mais favorecido tende a levar vantagem na disputa pelo prêmio, à revelia do verdadeiro esforço dos professores/diretores. Por outro lado, uma parcela significativa das escolas, as de pior desempenho relativo, não recebe nenhum incentivo para melhorar a qualidade da escola, pois não tem expectativas de alcançar os 100 primeiros lugares. Segundo, os professores/ diretores das escolas que, na margem, têm possibilidades efetivas de ganhar o prêmio, são incentivados a terem comportamentos oportunísticos. Isto porque taxas de reprovação ou evasão escolares, por exemplo, não são levadas em consideração na escolha das melhores escolas. Como decorrência desses fatores, é pouco provável que essa política contribua para a melhoria da qualidade da educação no estado.

Por fim, o Estado do Rio de Janeiro institui em 2000 o Programa Nova Escola que, desde então, vem sofrendo alterações anuais no seu formato. Essas mudanças retiram o caráter de continuidade que é fundamental para o bom funcionamento de um sistema de incentivos. Em 2004, as escolas passaram a ser avaliadas em função de três indicadores.

Primeiro, os resultados dos alunos nos testes de proficiência em língua portuguesa e matemática, sendo estabelecidos níveis mínimos de desempenho. Segundo, o fluxo escolar, ou a porcentagem dos alunos que permanecem matriculados na escola no final do período letivo e dão continuidade a seus estudos sem qualquer tipo de retenção ou reprovação. Terceiro, a gestão escolar que engloba: a transparência na prestação de contas dos recursos humanos e financeiros para os órgãos de fiscalização, a participação e integração da comunidade na escola e a gestão da matrícula escolar. Cada escola recebe uma nota para cada indicador, tendo os dois primeiros indicadores peso 2 e o última peso 1 . No final, em função das suas notas, as escolas são classificadas em cinco níveis. Cada um destes níveis representa uma gratificação diferente. Por exemplo, para o nível 5, o mais elevado, os professores de tempo integral e o pessoal de apoio receberam, respectivamente, R\$ 500 e R \$ 250, em 2004.

Além da falta de continuidade mencionada acima, existem alguns problemas neste programa do Rio de Janeiro. Assim como no caso do programa no Paraná, ele não classifica as escolas em função da sua verdadeira contribuição, ou seja, do valor agregado da mesma. Ademais, todos os níveis de escola, mesmo a de nível mais baixo, recebem gratificação, apesar de valores diferentes. Não existe um sistema de

\footnotetext{
${ }^{12}$ Em março de 2002, essa premiação correspondia a R \$ 800 e R \$ 300, respectivamente, para docentes e pessoal administrativo. Os melhores alunos também são premiados.
} 
penalidade para as escolas de pior avaliação. Um sistema mais completo, que envolve bonificações e penalidades, tende a apresentar um resultado mais eficaz.

Por fim, o foco da classificação das escolas deveria ser somente no desempenho dos alunos e no fluxo escolar, ou seja, na melhoria da qualidade da educação. Não parece adequado incorporar também o indicador gestão escolar. No caso da transparência na prestação de contas e da gestão da matrícula, essas deveriam ser uma obrigação da escola. No que diz respeito aos assuntos relacionados à integração da escola com a comunidade, as escolas são julgadas por itens tais como se a comunidade utiliza os equipamentos da escola nos finais de semana ou se os estudantes participam da vida escolar por meio do grêmio estudantil. Caso os diretores/professores julguem que se preocupar com estes fatores é importante para levar a uma melhoria no desempenho dos alunos, eles automaticamente adotariam políticas para incentivar essas ações por parte da comunidade ou do alunato já que buscariam alcançar um ranking melhor para a sua escola, com a conseqüente maior gratificação. Se os impactos dessas medidas não são vistos como significativos para acarretar uma melhoria no desempenho dos alunos, elas não deveriam ser adotadas, pois tiram o foco e recursos daquele que deveria ser o principal objetivo da política, qual seja, a qualidade da educação.

Em suma, é pouco provável que as experiências com a política de SA, nos âmbitos estadual e municipal, até o momento no Brasil tenham tido um impacto significativo sobre a qualidade da educação. Para um sistema de incentivos funcionar, é imprescindível que o seu formato seja bem desenhado. As experiências até o momento falham neste quesito.

\section{DIFICULDADES DE IMPLANTAR A SA}

O objetivo desta seção é discutir alguns dos principais empecilhos para a implantação de um política de SA no Brasil, em âmbito nacional, aos moldes da que vigora nos Estados Unidos depois da aprovação do NCLB.

O primeiro deles está relacionado com a forte tradição, seguida pelos profissionais que trabalham na área da educação no Brasil, de associar uma melhoria na qualidade da educação com a introdução de políticas que, quase que invariavelmente, significam aumentar os gastos.

O problema destas políticas é que as experiências brasileira e internacional sugerem que gastar mais não leva necessariamente a uma melhoria da qualidade do ensino. Hanushek (2003) faz uma extensiva revisão da literatura para os Estados Unidos e internacional sobre os possíveis impactos de diferentes políticas educacionais, que acarretam em mais gastos em educação. Alguns exemplos dessas políticas são os seguintes: aumentar os salários dos professores, reduzir o número de alunos em sala de aula, exigir um maior nível de escolaridade dos professores e melhorar a infra-estrutura nas escolas. Essas e outras variáveis afins não são significativas para explicar o desempenho escolar dos alunos e, por conseguinte, a qualidade da educação. 
Para que esta tradição seja rompida, é fundamental a ampla disseminação da evidência empírica que mostra a ineficiência das políticas comumente propostas. Com isto, reduz a resistência à aplicação de uma política como a de SA, que exige uma clara contrapartida na melhoria do desempenho dos alunos para que mais recursos sejam liberados. Ou seja, a lógica da política passa a ser atrelar recursos, inclusive maiores (ou menores) salários para professores e diretores de escola, a resultados. Desta forma, o educador fica responsável perante a sociedade pela aprendizagem dos alunos.

A forte oposição por parte de professores (e seus sindicatos) para uma política desta natureza é o segundo empecilho para sua adoção no Brasil. Atualmente, o salário do professor, basicamente, aumenta em função de dois fatores: sua titulação e sua experiência profissional. $O$ interessante é que a evidência empírica não indica que estes fatores são significativos para explicar o desempenho dos alunos. ${ }^{13}$ Portanto, a remuneração dos professores não é baseada naquilo que deveria ser, ou seja, na qualidade do ensino ou na sua capacidade de aumentar o aprendizado dos seus alunos.

Manter o atual formato de remuneração é conveniente para os professores, visto que não é difícil aumentar a titulação e obter experiência profissional. Afinal, existem vários cursos de capacitação dos professores com qualidade duvidosa e a experiência vem com a estabilidade no emprego. Facilidade que não existe quando o salário está atrelado à melhora no desempenho dos alunos.

Hanushek (1994) propõe duas estratégias para contornar a oposição dos professores, que leva em consideração a dificuldade de alterar o regime de trabalho dos mesmos, que tem a estabilidade no emprego como um direito adquirido. Primeiro, dar a opção para os atuais professores de mudar espontaneamente de regime de emprego. Ao invés da estabilidade, passar para um regime no qual o salário variável passa a ser uma parcela significativa do salário total (maior média e maior variância), sendo aquele determinado em grande medida pelo desempenho dos seus alunos. Segundo, obrigar os novos professores contratados a seguir com o novo regime de trabalho, sem estabilidade e com remuneração, atrelado ao desempenho dos alunos. Seria interessante analisar a viabilidade da adoção dessas alternativas no Brasil.

A terceira dificuldade para se adotar a política de SA está associado ao fato de que as políticas educacionais no Brasil não apresentam uma continuidade de médio e longo prazos, necessária para o sucesso. A experiência do "Boletim da Escola" no Estado do Paraná discutida acima é somente um exemplo: assim que o novo governo foi eleito, a política foi abandonada. Nas escolas, em geral, cada novo secretário de Educação introduz a sua política, sempre com a promessa de gerar uma "revolução" na educação. Essa realidade é retratada em Oliveira e Schwartzman (2002). Eles descrevem que as autoridades praticamente não se preocupam com os resultados dos seus programas. Os professores e as escolas não impõem resistências à sua

13 Para mais detalhes, ver Hanushek e Rivkin (2003). 
implementação, "porque sabem que o fôlego logo passa e tudo voltará ao 'normal' em breve. (Afinal), a melhor forma de não mudar é inovar sem cessar”.

Para evitar essa descontinuidade, o governo federal poderia aprovar no Congresso uma lei que estipule um prazo para todos os estados implantarem uma política de SA, deixando para cada um determinar os detalhes da sua legislação. Dado que a quase totalidade das escolas públicas são estaduais ou municipais e o governo federal basicamente somente transfere os recursos que são aplicados na educação básica, uma mudança de legislação neste sentido corresponderia a uma interferência do Executivo federal, via Congresso, em políticas de outras esferas de governo. O objetivo, no entanto, é dificultar a mudança da política de SA nos âmbitos estadual e municipal, uma vez adotada. Essa foi exatamente a estratégia seguida pelo governo dos Estados Unidos, quando implantou o NCLF em 2002, apesar de ser uma federação com muito maior independência dos seus membros. Portanto, é também passível de ser feito no Brasil. Inclusive, o país tem uma experiência recente nesta linha, quando aprovou o Fundef no Congresso em 1996. Esse estabeleceu, por exemplo, que $60 \%$ dos recursos da educação de estados e municípios devem ser destinados, exclusivamente, para salários dos profissionais do magistério na ativa.

Por fim, a adoção de uma política de SA exige autonomia para as escolas adotarem as políticas que elas considerem mais adequadas para melhorar o desempenho dos alunos. Essa autonomia não existe no sistema educacional brasileiro. As Secretarias de Educação exercem uma forte influência sobre as escolas, determinando e cobrando a adoção de políticas por elas decididas. Em outras palavras, existe um excesso de burocracia e uma forte intervenção na atuação das escolas. ${ }^{14}$ Será preciso alterar essa tradição intervencionista se os professores e diretores vão passar a ser julgados e remunerados pela qualidade da educação.

\section{CONCLUSÃO}

Existem algumas experiências recentes no Brasil, nos âmbitos federal, estadual e municipal, com alguma forma de política de SA. No entanto, tendo como base a experiência americana, é pouco provável que essas políticas tenham tido resultados significativos sobre o desempenho dos alunos. De uma maneira geral, elas não incorporam um sistema de incentivos no qual professores/diretores da escola sofrem penalidades ou recebem bonificações em função do desempenho dos seus alunos. Como visto na experiência americana, a política de SA somente é eficaz quando incorpora tal sistema.

É importante mencionar, no entanto, que não necessariamente o impacto da política de SA no Brasil será ou foi o mesmo do verificado nos Estados Unidos. É

\footnotetext{
${ }^{14}$ Para mais detalhes, ver Oliveira e Schwartzman (2002).
} 
imprescindível realizar uma análise empírica mais detalhada das experiências que já ocorreram no Brasil para se chegar a uma conclusão definitiva.

Adicionalmente, naquelas poucas experiências no Brasil que tentam incorporar algum sistema de incentivos, esse não é adequadamente estruturado. A principal falha é que não existe uma mensuração correta da contribuição da escola para o aprendizado, baseado no critério do valor adicionado. Escolas com notas maiores nos testes de proficiência recebem maiores bonificações mesmo se esses resultados estiverem relacionados com fatores fora do controle das escolas como, por exemplo, o background familiar dos seus alunos. Esse é o caso, por exemplo, do Programa Nova Escola do Estado do Rio de Janeiro.

Para a implantação da SA em âmbito nacional no Brasil, seria necessário contornar algumas dificuldades. Três delas se destacam. A primeira é a forte tradição no Brasil de associar uma melhoria na qualidade da educação com o aumento dos gastos. Para romper esta tradição, é fundamental a ampla disseminação da evidência empírica que mostra a ineficiência das políticas comumente propostas. A segunda dificuldade é a oposição, em geral, de professores (e seus sindicatos) a uma política que atrela seus salários a algum tipo de desempenho. A última é a falta de uma continuidade de médio e longo prazos das políticas educacionais no Brasil. Neste sentido, seria interessante que o governo federal aprovasse no Congresso uma lei que estipulasse um prazo para todos os estados brasileiros implantarem uma política de SA. Com isto, dado que a maioria das escolas públicas são estaduais e municipais, seria mais difícil um novo secretário de Educação, uma vez empossado, abandonar a SA, uma vez implantada. A percepção de continuidade por parte dos professores/ diretores é fundamental para o sucesso do sistema de incentivos inserido na política.

\section{REFERÊNCIAS BIBLIOGRÁFICAS}

ANDRADE, E. (2006); “Alternativa de política educacional para o Brasil: ‘School Accountability”; Mimeografado.

BRICKLEY, J.; SMITH, C.; ZIMMERMAN, J. (2004); Managerial Economics and Organizational Architecture; McGraw Hill.

CARNOY, M. e LOEB, S. (2002); "Does external accountability affect student outcomes? A crossstate analysis", Educational Evaluation and Policy Analysis, Winter.

HANUSHEK, E. (1994); “Making schools work: improving performance and controlling costs"; Washington D.C: Brookings Institution.

HANUSHEK, E. (2003); “The failure of input-based schooling policies”; The Economic Journal, February.

HANUSHEK, E. (2004); “United lessons about School Accountability”; CESifo DICE Report, 2(4), Winter.

HANUSHEK, E. e RAYMOND, M. (2002); "Lessons about the design of state accountability Systems"; em Paul E. PETERSON and Martin R. WEST (ed.), No Child Left Behind? The Politics and Practice of Accountability; Washington, DC: Brookings.

HANUSHEK, E. e RAYMOND, M. (2004); "Does school accountability lead to improved student performance?"; Journal of Policy Analysis and Management, Spring.

JACOB, B. (2002); "Accountability, incentives and behavior: the impact of high-stakes testing in the Chicago public schools"; NBER Working Paper \#8968.

OLIVEIRA, J. e SCHWARTZMAN, S. (2002); A Escola Vista por Dentro; Editora Alfa Educativa. 